\title{
ISONOMIA NA TRIBUTAÇÃO EXTRAFISCAL
}

André Folloni

EQUALITY IN TAXATION FOR NON FISCAL PURPOSES

\section{RESUMO}

NOS ÚlTIMOS ANOS, O BRASIL TEM UTILIZADO FREQUENTEMENTE A tRIBUTAÇÃO COMO MEIO DE INDUÇÃO DAS ATIVIDADES ECONÔMICAS, PRETENDENDO ATINGIR OBJETIVOS DE REGULAÇĀO DA ECONOMIA. ESSE USO DA TRIBUTAÇĀO ENQUADRA-SE NAQUILO QUE A DOUTRINA, TRADICIONALMENTE, DENOMINA "TRIBUTAÇÃO extrafiscal" ou "extrafiscalidade". Ela provoca uma DIFERENCIAÇÃO ENTRE OS CONTRIBUINTES: AQUELES QUE JÁ REALIZAM A CONDUTA PRETENDIDA PELO PODER PÚBLICO E QUE, POR ISSO, NÃO SERÃO AFETADOS PELA TRIBUTAÇÃO EXTRAFISCAL, E OS QUE NÃO A REALIZAM, E QUE SERÃO OS DESTINATÁRIOS DESSA TRIBUTAÇÃO. CRIANDO UMA DIFERENCIAÇÃO, ESSA FORMA DE TRIBUTAÇÃO ESTÁ SUJEITA AO CONTROLE JURídico dA IGUALDADE. PoRÉm, OS APARATOS DOUTRINÁRIOS TRADICIONAIS DE CONTROLE DA IGUALDADE NO DIREITO TRIBUTÁRIO, DERIVADOS DA CAPACIDADE CONTRIBUTIVA, NÄO SE APLICAM PLENAMENTE À TRIBUTACC̄̃ EXTRAFISCAL. ESTE ARTIGO INVESTIGA A PROPORCIONALIDADE COMO CRITÉRIO DE CONTROLE DA VALIDADE DAS DESIGUALDADES CRIADAS, PELO ESTADO, AO TRIBUTAR COM O OBJETIVO DE INTERFERIR NA ECONOMIA, DIRECIONANDO-A PARA A PROMOÇÃO DE CERTAS FINALIDADES.

\section{PALAVRAS-CHAVE}

Intervenção do Estado; Desenvolvimento; Tributação; EXTRAFISCALIDADE; IGUALDADE.

\author{
ABSTRACT \\ IN RECENT YEARS, BRAZIL HAS OFTEN USED TAXATION TO \\ INDUCT ECONOMIC ACTIVITIES, INTENDING TO ACHIEVE THE \\ GOALS OF REGULATING THE ECONOMY. THIS USE OF TAXATION \\ FALLS ON WHAT THE LAW THEORY TRADITIONALLY CALL \\ "EXTRAFISCAL TAXATION". IT CAUSES A DIFFERENTIATION \\ BETWEEN TAXPAYERS: THOSE WHO ALREADY PERFORM THE \\ CONDUCT DESIRED BY THE GOVERNMENT AND THEREFORE \\ WILL NOT BE AFFECTED BY EXTRAFISCAL TAXATION, \\ AND THOSE WHO DO NOT REALIZE IT, AND THAT WILL \\ BE THE RECIPIENTS OF SUCH TAXATION. CREATING A \\ DIFFERENTIATION, THIS FORM OF TAXATION IS SUBJECT TO \\ THE LEGAL CONTROL OF EQUALITY. BUT THE TRADITIONAL \\ DOCTRINAL WAYS OF EQUALITY CONTROL IN TAX LAW, DERIVED \\ FROM THE ABILITY TO PAY, ARE NOT FULLY APPLY TO THIS \\ TYPE OF TAXATION. THIS PAPER INVESTIGATES HOW THE \\ PROPORTIONALITY CRITERION VALIDITY CONTROL OF \\ INEQUALITIES CREATED BY THE STATE TO TAX IN ORDER \\ TO INTERFERE IN THE ECONOMY, DIRECTING IT TO PROMOTE \\ CERTAIN PURPOSES.

\section{KEYWORDS} \\ StATE INTERVENTION; DEVELOPMENT; TAXation; \\ EXTRAFISCALITY; EQUALITY.
}

\section{INTRODUÇÃO}

O Estado brasileiro contemporâneo tem utilizado, com frequência e vigor, tributos para regular a economia e influir nas tomadas de decisão adotadas pelos agentes econômi$\cos$, dirigindo suas atividades. É um Estado que tem procurado influenciar cidadãos e 
empresas em suas decisões econômicas. Adéqua-se, assim, à categoria dos "Estados incitadores”, produtores de influências (MARTINS-COSTA, 2005, p. 137).

Nos últimos anos, há vários exemplos desse tipo de ação. Para enfrentar a crise econômica no início de 2009, por exemplo, houve a redução do IPI para os veículos, depois estendida para os eletrodomésticos da "linha branca". Essa alteração na política fiscal e nas normas de direito tributário procurou influenciar as decisões tomadas por cidadãos consumidores e indústrias automobilísticas, e fomentar uma economia que tendia a desacelerar, em atuação anticíclica. Mais recentemente, houve o estabelecimento de diferença no IPI para os veículos importados - ou produzidos, no Brasil, com alto índice de industrialização no exterior -, em relação aos veículos de produção nacional ou com alto índice de industrialização interna. A política fiscal, nesse caso, implicou maior carga tributária para os veículos importados. Sofreu o impacto do direito tributário, pois a regra constitucional da anterioridade nonagesimal, prescrita no art. 150, III, c, inicialmente desrespeitada, teve sua eficácia garantida pelo Supremo Tribunal Federal, em despacho proferido na Ação Direta de Inconstitucionalidade n. 4.661. E pode vir a sofrer novo impacto, pois o art. III, 1 e 2, da Parte II, do Acordo Geral de Tarifas e Comércio - GATT, impõe a regra da não discriminação, por tributos internos, como o IPI, entre mercadorias nacionais e importadas, discriminação que acabou ocorrendo.

O tema, portanto, merece atenção da doutrina e da comunidade jurídica como um todo. O presente artigo propõe-se a examinar os critérios de isonomia a serem verificados quando da utilização dos tributos como meio de direcionamento da economia, num aspecto daquilo que se convencionou chamar de "função extrafiscal" dos tributos.

\section{JUSTIÇA E IGUALDADE NA TRADIÇÃO DA DOUTRINA TRIBUTARISTA: O REDUCIONISMO EPISTEMOLÓGICO}

A doutrina tributarista, no Brasil, costuma limitar duplamente sua apreensão a respeito dos temas da justiça tributária. Em primeiro lugar, limita-a porque a reduz, praticamente, à igualdade tributária e à capacidade contributiva, num expediente redutor, que separa o direito tributário da destinação do produto da arrecadação ou dos efeitos concretos gerados na vida dos contribuintes. Em segundo lugar, limita-a porque reduz seu exame, normalmente, aos tributos com função arrecadatória - a tradicional função fiscal dos tributos. Novo expediente redutor, a cindir o direito tributário da política fiscal.

Na primeira redução, a doutrina equipara a tributação justa àquela que obedece ao princípio da igualdade tributária. Esse princípio, no direito brasileiro, é compreendido pela conjugação de dois preceitos constitucionais: a capacidade contributiva, princípio geral do sistema tributário nacional ( $\mathrm{CF}$, art. $145, \S 1^{\circ}$, ab initio), e a igualdade 
enquanto limitação ao poder de tributar (CF, art. 150, II). Assim, em primeiro lugar, e por força desse último dispositivo, será justo o tributo que incida uniformemente sobre todos aqueles contribuintes que se encontram em situação equivalente. E, em segundo lugar, por força do primeiro preceito, será justo o tributo que incida, proporcional e gradualmente, sobre contribuintes que se encontrem em situação econômica diferente, na medida dessa diferença. Contribuintes com maior capacidade econômica devem sofrer incidência tributária proporcionalmente mais agravada do que aqueles com menor capacidade.

Essa visão é redutora porque, em seus efeitos, vistos sob perspectiva pragmática, acaba por concluir que será justa a tributação que incida igualitariamente sobre todos os contribuintes - ainda que incida de forma igualmente injusta sobre todos! Uma visão redutora, apertada, estreita, que pense apenas a norma que determina o pagamento e nada mais, talvez possa chegar legitimamente a essa conclusão. Porém um entendimento ampliado, aberto, que enfrente as complexidades da sociedade contemporânea e do direito que a conforma, não se poderá satisfazer com ela. Um Estado que tribute excessivamente a todos os cidadãos e não lhes devolva serviços e obras públicas adequadas, ou que desvie os recursos arrecadados em práticas de corrupção sistêmicas, não praticará tributação justa. Ainda que, eventualmente, seja tributação igualitária. Justiça tributária e igualdade tributária, em uma visão ampla e complexa, não são o mesmo.

O segundo aspecto reducionista dessa concepção de justiça tributária revela-se quando se percebe que, a ela, subjaz uma racionalidade que se volta aos tributos fiscais aqueles cuja função precípua é arrecadar divisas para o Estado. Se se define o tributo extrafiscal por sua função, pelas intenções do governo ao concebê-lo, ou por seus efeitos nas condutas do cidadão contribuinte ou na economia, então ele é definido a partir de elementos que se encontram fora das cogitações da dogmática jurídico-tributária tradicional - que é reducionista por decisão metodológica autoimposta. Uma ciência do direito tributário em sentido estrito, na forma preconizada pela doutrina tributarista, nada teria a dizer a respeito da função das normas na vida socioeconômica - seria trabalho de sociólogos ou economistas. Nada teria a falar sobre intenções governamentais - seria função de políticos. Não se poderia manifestar a respeito dos efeitos concretos que as normas causam nas condutas dos sujeitos atingidos por elas - seria ofício dos sociólogos do direito. Sob essa regra metodológica, baseada em pressupostos epistemológicos não só questionáveis como infundados, e geradora de uma ética epistêmica de irresponsabilidade social pelos efeitos das propostas teóricas, a extrafiscalidade tributária, em rigor, seria tema quase interditado às preocupações do estudioso do direito tributário.

No plano estritamente fiscal dos tributos, e pela mão da dogmática jurídico-tributária tradicional, a justiça é indevidamente reduzida à isonomia. Esta, agora corretamente, é construída a partir dos preceitos constitucionais da capacidade contributiva e da igualdade tributária. 


\section{EXTRAFiscalidade, PRAgmática}

\section{E DIRECIONAMENTO ESTATAL DA ECONOMIA}

Surge nova via de estudos a respeito do fenômeno tributário quando o jurista se abre para o plano pragmático da realidade jurídica. Porque o tributo é, comumente, utilizado com a finalidade específica de gerar determinados efeitos na conduta do destinatário da norma tributária - especialmente, das atividades econômicas. Alfredo Augusto Becker, na virada da década de 1950 para a década de 1960, já via essa atividade como o futuro da tributação no mundo - em parte fundamental da sua obra, esquecida e subjugada pela doutrina, que enfatizou, quase com exclusividade, o aspecto estrutural de sua Teoria geral do direito tributário.

Direito é muito mais que linguagem, mas é fundamentalmente linguagem. Enquanto tal, merece atenção integrada a seus planos sintático, semântico e pragmático. A doutrina debruça-se sobre os primeiros, mas, em atitude redutora, afasta o último inclusive, em expediente saudavelmente reflexivo, denomina-se "lógico-semântica", ao universalizar suas concepções para o âmbito da teoria geral do direito (CARVALHO, 2009 , passim). Nesses planos sintático e semântico, a doutrina volta-se para o ordenamento visto, por assim dizer, de dentro. Examina os inter-relacionamentos que as normas mantêm umas com as outras - plano sintático - e, na concepção de "plano semântico" que costuma adotar, investiga o significado das palavras integrantes do direito positivo. Mas deixa de investigar os efeitos que essas normas podem gerar nas pessoas que, de uma forma ou de outra, sentem as consequências do direito tributário. Nesse conjunto estão os sujeitos passivos da obrigação tributária, principal e acessória; o órgão tributante; estrangeiros, cuja decisão de negócios será afetada; organizações internacionais ou comunitárias; os cidadãos em geral, inclusive não contribuintes, direta ou indiretamente, daquele tributo em específico etc. Um vastíssimo mundo ligado ao direito tributário fica, inaceitavelmente, excluído do objeto de estudo do tributarista.

Dentre os temas que esse reducionismo epistemológico tem excluído da apreciação de boa parte da doutrina tributarista está o direcionamento estatal da economia por meio dos tributos. O Estado usa tributos para conduzir a economia - eficaz ou ineficazmente, de forma legítima ou não, com justiça ou sem justiça, desastradamente ou com sabedoria. É onde o direito tributário encontra e confunde-se com o direito econômico, a disciplina jurídica da intervenção do Estado na economia. Sobre essa relevantíssima atividade estatal, pouco se sabe na doutrina tributarista, o que é de todo lamentável. Cumpre trabalhar para suprir essa lacuna. Nada fácil a empreitada, contudo, que precisará aprender a conviver com a presença do erro na pesquisa científica (BORGES, 2012, p. 35-41).

Essa intervenção estatal na economia por via tributária pode se dar de formas diferentes. Pode decorrer da criação de tributos propriamente fiscais, assim entendidos aqueles criados com a intenção preponderante de arrecadar divisas para o 
patrimônio público. Tributos fiscais elevados, municipais ou estaduais, podem acabar induzindo as atividades econômicas a evitar a ocorrência do fato gerador naquela localidade, deslocando espacialmente a incidência, por exemplo. Daí se nota que a indução estatal dos comportamentos econômicos pode ser, até mesmo, involuntária e imprevisível (COSTA, 2005, p. X). São tributos intencionalmente fiscais, com efeitos indutores (SCHOUERI, 2005, p. 29). A “ecologia da ação”, categoria da epistemologia da complexidade, explica-o, e revela-se útil para a compreensão do direito tributário: muitas vezes, uma determinada ação, quando posta no jogo de complexidades da realidade, assume novas configurações, e gera efeitos não previsíveis ou desejáveis por seu ator. Apenas um pensamento pragmático, preocupado com os efeitos das normas jurídicas, poderá considerá-la (FOLLONI, 2013, p. 380 e ss.).

Além disso, a intervenção estatal sobre a economia, dirigindo-a para determinadas direções, pode ser feita intencionalmente - com ou sem êxito. E isso, por meio de tributos usados especificamente para esse fim, independentemente, em muitos casos, de preocupações com a arrecadação tributária. Um tributo essencialmente interventor; uma manifestação da extrafiscalidade.

Tributos extrafiscais, em sentido estrito, são aqueles concebidos com finalidade diversa da arrecadação: seu objetivo principal é induzir os contribuintes a fazerem ou a não fazerem algo. Objetivam influenciar na tomada de decisão dos cidadãos, direcionar os comportamentos socioeconômicos, estimulando-os ou desestimulando-os, ao torná-los, por meio da exação, mais ou menos custosos. Por isso, afetam, na prática, direitos de liberdade (ATALIBA, 1968, p. 150-151; SCHOUERI, 2005, p. 32-33; ÁVILA, 2009, p. 98; ÁVILA, 2012-a, p. 432; CARRAZZA, 2011, p. 118; BORGES, 1998, p. 46-47; MARINS; TEODOROVICZ, 2010, p. 76-77). A indução do comportamento é feita pela via econômica, na pressuposição da ausência de norma que o proíba ou obrigue. Ou seja: juridicamente, o comportamento é lícito: tanto pode ser quanto pode não ser adotado, e nenhuma sanção a ele se pospõe. Mas, economicamente, torna-se mais ou menos atrativa sua adoção, e o elemento tributário é determinante nessa mutação. Nas abstrações jurídicas, como o comportamento é permitido, ou facultado, sua adoção é livre; como, na práxis da vida real, o comportamento acaba sendo induzido, muitas vezes, com tal intensidade que se torna proibitivo ou de realização inevitável, a regra tributária afeta, sem dúvida, a liberdade de opção individual. É o direito, mesmo não proibindo, tornando um comportamento proibitivo. $\mathrm{Ou}$, mesmo não obrigando, tornando-o de adoção praticamente obrigatória. Outro motivo para que o jurista não se apegue, exclusivamente, às abstrações dos modais deônticos: sob o modal permitido ou facultado, pode ocultar-se uma normatividade jurídica que, na prática, não deixe opção ao cidadão.

Outras duas ponderações devem ser feitas. A primeira: se é verdade que, no mais das vezes, mesmo os tributos com função preponderantemente indutora de comportamentos também arrecadam, isso nem sempre ocorre. A “Curva de Laffer” demonstra-o. 
$\mathrm{O}$ aumento na alíquota de um tributo pode, num primeiro momento, produzir crescimento de arrecadação. Contudo, em momento posterior, se o tributo for aumentado de forma excessiva, a arrecadação pode decrescer, porque a realização do fato gerador se revela inviável economicamente. Isso leva à segunda ponderação: se é assim, então um governo organizado e competente não pode depender, em termos de arrecadação, dos tributos extrafiscais. Ao contrário: deve poder prescindir do produto de sua arrecadação a qualquer momento. Deve estar economicamente equilibrado para poder reduzir o tributo, drasticamente, para fomentar comportamentos econômicos; ou aumentá-lo, intensamente, para coibi-los, até o limite de anular sua arrecadação com aquele tributo - que existiria em abstrato, mas não incidiria em concreto. Nota-se a dificuldade, em termos de finanças públicas e de equilíbrio fiscal, para a implementação de condições adequadas para a tributação extrafiscal - o que justifica seja ela, inclusive, posta em questão, no que diz respeito à sua viabilidade nesse grau máximo de eficácia, notadamente em países com dificuldades econômico-financeiras.

Fica claro, então, que tanto os tributos concebidos para serem fiscais quanto aqueles pensados com intenção de extrafiscalidade podem ter efeitos indutores de comportamentos. Para compreender esses efeitos indutores, é preciso que a dogmática jurídica tradicional complexifique seu discurso para abranger também temas que, tradicionalmente, ficaram para a política fiscal - a concepção dos tributos, a intenção que presidiu sua criação em abstrato - e para a sociologia jurídica - a eficácia social das normas, os efeitos que elas geram no comportamento de seus destinatários, em preocupação pragmática. Boa parte da construção teórica a respeito da extrafiscalidade está nos clássicos de ciência das finanças, economia e política fiscal, desconhecidos de grande parcela de jovens estudiosos. Cumpre aos tributaristas do século XXI, já conhecedores de toda a tradição doutrinária estritamente jurídica construída no último meio século no Brasil, recuperar aquelas lições. Agora, graças ao sério e dedicado trabalho desenvolvido nos últimos cinquenta anos, devemos ter sabedoria suficiente para entender onde inserir e o que fazer com aquele rico conhecimento de ciências sociais, e como relacioná-lo com o direito tributário, sem cairmos naquele "coquetel" ou "enciclopédia" de que falava Alfredo Augusto Becker (BORGES, 2012, p. 407).

Dentre os efeitos indutores de comportamentos, pode estar a intervenção sobre o domínio econômico, para direcionar as atividades econômicas em uma ou outra senda ou várias, inclusive o desenvolvimento sustentável. O objeto deste estudo é, no entanto, delimitado: se o Estado opta por introduzir tributação extrafiscal, quais são os critérios de igualdade que devem ser observados?

\section{FunÇÃo Fiscal E IGUALdAde:}

\section{CAPACIDADE CONTRIBUTIVA E SEU FUNDAMENTO}

A doutrina tributarista não diverge em encontrar, na capacidade contributiva, o critério 
de igualdade tributária nos tributos fiscais - assim entendidos, aqui, como aqueles concebidos com a intenção preponderante de arrecadar. Não discriminar os contribuintes que se encontram em situação equivalente, e diferenciar, na medida das desigualdades, os contribuintes em situação não equivalente, deve ser feito tomando-se, como parâmetro de medida de equivalência, a capacidade contributiva (TIPKE; LANG, 2008, p. 200; MOLINA, 1998, p. 73; ÁVILA, 2009, p. 160; ÁVILA, 2001, p. 31; COSTA, 2003, p. 37; CARRAZZA, 2011, p. 99; CARRAZZA, 2005, p. 304; VIEIRA, 2013, p. 23).

Klaus Vogel faz interessante reflexão, na qual distingue subfunções da tributação, além da função de arrecadação. Dentre essas subfunções, aparece a de distribuir a carga tributária, expediente que deve levar em consideração critérios de justiça e isonomia (1977, p. 106). Não basta arrecadar, mas é preciso arrecadar distribuindo o ônus da tributação de forma igualitária entre os contribuintes. Nos tributos cuja função principal é arrecadar, a subfunção de distribuição equânime e proporcional do ônus entre os contribuintes deve estar presente.

Se é assim, a medida da equalização deve ser interna aos próprios contribuintes, e a capacidade contributiva atende a esse mandamento (ÁVILA, 2009, p. 160-161). Há, portanto, um fundamento racional a sustentar a capacidade contributiva como critério de aferição da igualdade entre contribuintes, no caso dos tributos fiscais - além, é claro, no ordenamento brasileiro, do fundamento jurídico-positivo ( $\mathrm{CF}$, art. $145, \S 1^{\circ}$ ).

\section{FunÇÃo EXTRAFISCAL E IGUALDAde:}

\section{CAPACIDADE CONTRIBUTIVA E SUAS INCONSISTÊNCIAS}

Paralela à subfunção de distribuição da carga entre os contribuintes, existe a subfunção, eventualmente presente nos tributos, de induzir comportamentos. É a função extrafiscal - que, como visto, pode, no limite, anular a função arrecadadora.

Sendo uma função paralela à de arrecadação e de distribuição da carga tributária, a doutrina aponta não ser, a capacidade econômica, em relação ao peso dessa carga, o critério adequado de comparação entre os contribuintes, para aferição do respeito à igualdade. Nesse sentido, não há coerência em pretender-se partilhar o ônus de um tributo extrafiscal, entre os contribuintes, de acordo com sua capacidade contributiva, pois o objetivo desse tributo não é arrecadar, e a lógica que o governa não é a preocupação com a adequada distribuição dos ônus financeiros da tributação (ÁVILA, 2009, p. 161-162; ÁVILA, 2012-a, 432-433). Excetua-se dos tributos extrafiscais, por isso, a necessidade de submeter os contribuintes com idêntica capacidade contributiva aos mesmos regimes tributários, e de diferenciar os regimes tributários dos contribuintes com capacidade econômica diversa (BORGES, 2001, p. 46). Como a função extrafiscal objetiva a busca por finalidades externas à arrecadação fiscal, o que deve ser feito é precisamente o controle da correção jurídica das medidas que 
visam o atingimento de tais finalidades, inclusive no que diz respeito à isonomia. Mas essas medidas, num primeiro momento, nada teriam a ver com a capacidade econômica dos contribuintes, e certamente não se justificaria diferenciação entre eles por esse critério (NABAIS, 1998, p. 658).

O propósito da tributação extrafiscal é influenciar comportamentos não qualificados, juridicamente, como proibidos ou obrigatórios. São condutas juridicamente permitidas, porque não modalizadas, pela lei, de forma diversa ( $\mathrm{CF}$, art. $5^{\circ}$, II). Num conceito estrito de licitude, são condutas lícitas. ${ }^{1}$ Porém, diante de princípios e valores constitucionais, é relevante que, mesmo permitidas, sejam conduzidas para uma ou outra direção - isto é, não fiquem totalmente livres.

Por isso, a tributação extrafiscal, como visto, até mesmo independentemente do efetivo pagamento do tributo, destinar-se-á a induzir alguém a fazer ou a deixar de fazer alguma coisa. Se é destinada a induzir a fazer algo, destina-se àqueles que não fazem esse algo; para aqueles que já fazem, a tributação extrafiscal será, no mais das vezes, irrelevante. Ao contrário, se é destinada a induzir a não fazer algo, destina-se àqueles que fazem esse algo, para que diminuam ou cessem tal fazer, e não àqueles que já não o fazem.

Como se percebe, a tributação extrafiscal secciona os contribuintes em dois grupos. Num primeiro grupo, inclui aqueles que são os seus destinatários, e que serão por ela atingidos, porque adotam - ou não adotam - os comportamentos que a tributação extrafiscal quer coibir - ou estimular. No segundo grupo, inclui aqueles que não são os seus destinatários, porque já adotam o comportamento desejado. Do grupo dos destinatários, os não destinatários estão excluídos, e vice-versa.

Por exemplo, imagine uma tributação extrafiscal que objetive o aumento da produção nacional de veículos industrializados. Para tanto, impõe ônus maior para os automóveis de baixo grau de produção industrial nacional. Ela não terá como destinatários os produtores nacionais, mas os importadores. Então, seccionará os contribuintes em dois grupos. No grupo dos não destinatários, estarão aqueles que já têm determinado grau de produção nacional, que não serão diretamente atingidos pela regra tributária extrafiscal como seus destinatários imediatos. No grupo dos destinatários, diretamente atingidos pela tributação extrafiscal, estão aqueles que não têm esse grau de produção interna.

Isso demonstra que a tributação extrafiscal é capaz de criar diferenciação entre os contribuintes. Porque os separa, ao menos, em duas classes bem definidas: aqueles que já seguem a orientação finalística que a tributação extrafiscal pretende atingir e, por isso, não são seus destinatários; e aqueles que não a seguem e, por isso mesmo, são seus destinatários. Se há uma diferenciação, há potencial ferimento à igualdade, que é princípio constitucional dos mais elevados no nosso sistema. É preciso saber, portanto, se essa diferenciação é válida. E, à exata medida da importância da igualdade no ordenamento, o controle da validade da diferenciação deve ser especialmente rigoroso. 
Essa pode ser chamada de uma diferenciação interclasses: o que se pretende avaliar é se a separação dos contribuintes entre duas classes - os destinatários imediatos da tributação extrafiscal e os não destinatários - é juridicamente válida, sob o ponto de vista da igualdade tributária. É uma avaliação feita sob um ponto de vista externo às classes, ou exógeno. Uma comparação entre os contribuintes destinatários da tributação extrafiscal - aqueles cujas condutas pretende-se sejam alteradas pela regra tributária - e os contribuintes não destinatários da tributação extrafiscal. Olhando-se, de fora, para as classes, compara-se os destinatários e os não destinatários. A capacidade contributiva, aqui, de fato, não é critério hábil para aferir a validade da discriminação entre as duas classes. Sob o ponto de vista externo, exógeno, ou interclasses, para aferir se a diferenciação adotada é válida, ao incluir alguns contribuintes na classe dos destinatários da tributação extrafiscal e excluir outros, a capacidade contributiva nada tem a dizer.

A adoção de tributo extrafiscal que dificulte determinada conduta e, com isso, induza outras diferenciará entre os contribuintes que praticam ou pretendem praticar a conduta afetada e os que não a praticam nem pretendem praticar. No exemplo: aumentar o IPI para veículos importados e manter inalterado o IPI dos veículos nacionais afeta as atividades de importação e venda de veículos importados, diferenciando-as em relação às atividades de fabricação e venda de veículos nacionais. Verificar a correção jurídica - validade - dessa diferenciação implica, além de outros exames, avaliar o respeito à igualdade. A capacidade contributiva, aqui, não será relevante. Não é aferindo a capacidade econômica das montadoras nacionais e dos importadores, ou dos consumidores de automóveis brasileiros, chineses, coreanos, alemães ou franceses, que se julgará, adequadamente, o respeito à igualdade tributária. O que se pretende, com a tributação, é algo externo, tanto à arrecadação quanto ao próprio contribuinte: um fim diverso, socioeconômico. A capacidade econômica do contribuinte não é o critério de aferição da igualdade interclasses nos tributos extrafiscais.

\section{FunÇÃo EXTRAFiscAl E IGUALdAde:}

\section{CAPACIDADE CONTRIBUTIVA E SUA RELEVÂNCIA}

Isso não significa, porém, que a capacidade contributiva não tenha qualquer aplicabilidade em relação aos tributos extrafiscais. Também em relação à tributação extrafiscal, a capacidade contributiva mostra sua relevância.

Nos Estados Democráticos de Direito contemporâneos, pela longa tradição que recebe e pelo sistema econômico com o qual convive, o direito trabalha com lógica patrimonial e econômica. Exceto parcela da esfera criminal, o direito, em última instância, acaba por transformar tudo em dinheiro. Ilícitos são punidos com penas pecuniárias. O dano moral - e, agora, o afetivo - é indenizado em dinheiro. O resultado disso 
é que aqueles com grande capacidade econômica podem fazer um juízo de utilidade e optar pelo ilícito, avaliando o ganho em face da perda - pagamento da multa. É assim que, por exemplo, um candidato a cargo eletivo pode acumular multas no período de campanha e, mesmo assim, eleger-se violando as leis eleitorais, se tiver capacidade econômica para tanto. Terá vencido as eleições na base da ilicitude, e o direito dar-seá por satisfeito, porque o ilícito foi punido e a pena foi cumprida.

Isso demonstra que, se a intenção do tributo extrafiscal for coibir comportamentos constitucionalmente indesejados - por exemplo, poluentes ou degradadores do ecossistema -, de nada adiantará tributação extrafiscal em bases que só coíbam determinados contribuintes, mas insuficientes para atingir a todos. Não só de nada adiantará, como será juridicamente ilícita essa tributação. De um lado, será tributação ineficiente; de outro, será desigual. Um tributo, por exemplo, destinado a impedir o desmatamento ou a produção industrial poluidora, que possa ser suportado por grandes corporações de fartas capacidades econômicas, será tão ineficaz quanto desigual: apenas impedirá a conduta daqueles contribuintes menos capazes economicamente, mas não de todos. E tributos extrafiscais, preleciona clássica doutrina, prestam-se a tornar determinada atividade não só menos conveniente como, em alguns casos, reprimir, frear a conduta, tornando-a praticamente impossível (GRIZIOTTI, 1959, p. 4; BLUMENSTEIN, 1951, p. 8). Não o será, todavia, se o mal dimensionamento do ônus tributário vier a tornar aquela conduta impossível apenas para uns, e não para outros. No plano pragmático, a igualdade estará violada.

A capacidade contributiva é "princípio geral" do sistema constitucional tributário brasileiro $\left(\mathrm{CF}\right.$, art. $\left.145, \S 1^{\circ}\right)$. Deve ter algo a dizer em relação ao direito tributário como um todo, inclusive no âmbito extrafiscal - o extrafiscal, embora a expressão pudesse induzir a entendimento diverso, é ainda tributário, sujeito ao regime jurídico tributário (SCHOUERI, 2005, p. 34). A doutrina cogita da capacidade contributiva como capaz de impor limites à tributação extrafiscal. Esse princípio protegeria o mínimo existencial da tributação baseada em extrafiscalidade e vedaria o confisco. ${ }^{2}$ Para além disso, a capacidade contributiva tem voz nos tributos extrafiscais, por outros motivos racional e juridicamente válidos: levá-la em consideração, sob um ponto de vista, contribuirá com a eficiência da tributação extrafiscal e, de outro lado, contribuirá para que se evite situações de desrespeito à isonomia.

De fato, a capacidade econômica deve ser levada em consideração também nos tributos extrafiscais. Não para graduar o tributo conforme a capacidade dos contribuintes, mas para definir um parâmetro de tributação que atinja a todos na indução de comportamentos, isto é, que interfira na liberdade individual de todos da mesma forma. Que seja capaz de superar diferenças de capacidade econômica entre os contribuintes para, efetivamente, pressionar todos a adotar a conduta constitucionalmente adequada, não permitindo que os mais ricos possam viver à margem da Constituição. A capacidade contributiva é manifestação da isonomia tributária interna ou endógena nos tributos 
extrafiscais: interna no sentido de que a capacidade econômica dos contribuintes postos na classe dos destinatários da tributação extrafiscal deve ser levada em conta pela regra tributária. Vistos do interior ou para dentro da classe dos destinatários, os contribuintes devem ter suas capacidades econômicas levadas em consideração.

Se a tributação extrafiscal visa estimular ou desestimular uma conduta qualquer, ela diferenciará os contribuintes, separando-os em classes, como visto. Em uma classe, ficam aqueles que não realizam - ou já realizam, conforme o caso - aquela conduta e, portanto, não serão afetados pela tributação. Na outra, ficam os que realizam - ou não realizam - a conduta e, por isso, sofrerão os efeitos estimulantes - ou desestimulantes - da regra tributária. Imagine-se tributação extrafiscal, por exemplo, preocupada com o desenvolvimento sustentável, que aumenta a tributação sobre a produção industrial daqueles contribuintes que não implementam adequados meios de logística reversa e de tratamento de resíduos da produção, com o objetivo de estimular a adoção desses meios. Essa tributação diferencia os contribuintes em duas classes. Há a classe daqueles que já têm implementados esses meios e, portanto, não são seus destinatários. E há o grupo daqueles que não os têm e, então, deverão sofrer seus efeitos. Criam-se, assim, duas classes de contribuintes: os destinatários da tributação extrafiscal e os não destinatários.

Entre os contribuintes inseridos no interior da classe dos destinatários da tributação extrafiscal - isto é, do mesmo regime de tributação extrafiscal, compartilhando o mesmo ônus tributário destinado a provocar condutas omissivas ou comissivas -, a capacidade contributiva deve ser levada em conta, para que eventuais diferenças de capacidade econômica não gerem desigualdade e ineficácia parcial da medida. Isso auxiliará a evitar que contribuintes com maior capacidade econômica possam internalizar o custo tributário e permanecer realizando a conduta que a norma tributária pretende desestimular, enquanto outros contribuintes, com menor capacidade econômica, serão obrigados a modificar seus comportamentos. No exemplo, evitará que alguns contribuintes internalizem o custo, eventualmente reduzindo lucros, e não adotem os meios de logística reversa, enquanto outros, menos capazes, não terão essa alternativa. Claro está que o critério não é suficiente, porque outros meios poderão ser adotados pelo contribuinte, se houver possibilidade, para reduzir ou eliminar a eficácia da tributação extrafiscal: aumento de preços, redução de outros custos etc. A complexidade do tema manifesta-se, levando à perplexidade do estudioso. Ainda assim, é um critério relevante e que deve ser afirmado pela doutrina. A afirmação do critério minará, simultaneamente, dois problemas: a ineficácia parcial da tributação extrafiscal e efeitos anti-isonômicos decorrentes da má elaboração da norma tributária.

Em síntese: sob o ponto de vista interno, endógeno, ou intraclasse, para aferir se há diferenciação entre os contribuintes postos dentro da classe dos destinatários da tributação extrafiscal, a capacidade contributiva tem muito a dizer. Se ela não for levada 
em consideração, haverá desigualdade nos efeitos da tributação extrafiscal, de modo que contribuintes com capacidade econômica elevada se submeterão a ela com efeitos diferentes daqueles contribuintes de menor capacidade econômica. Diferenciação como essa, no entanto, não encontra guarida na Constituição da República.

\section{FUnÇÃO FISCAL E IGUALDADE: PROPORCIONALIDADE}

Há casos, decerto raros, em que poderá inexistir a distinção aqui pensada: todos os contribuintes serão destinatários da tributação extrafiscal. Nesses casos, eventual distinção entre os contribuintes existirá apenas dentro da classe dos destinatários - é uma distinção interna, endógena, intraclasse, dependente da capacidade contributiva. Quando a separação entre os destinatários e os não destinatários existir, porém, é constitucionalmente obrigatório que seja aferida a validade jurídica dessa desigualdade interclasses. Dessa imposição, a uns, de mitigação em seus direitos de liberdade pela tributação extrafiscal, mas não a outros. Como visto, para o exame da validade da desigualdade externa, exógena ou interclasses na tributação extrafiscal, a capacidade econômica dos contribuintes não é critério adequado, diferentemente do que ocorre com a desigualdade interna, endógena ou intraclasse.

A instituição de tributação extrafiscal é feita como meio para atingir determinadas finalidades - que serão legítimas à medida que encontrem amparo constitucional. A existência - e eventual cobrança - da exação é pensada como meio para que certa finalidade seja concretizada. Trata-se da adoção de meios, na legislação infraconstitucional, para a consecução de fins prescritos em princípios constitucionais, devendo haver suficiente e demonstrada relação meio-fim. Esses meios adotados podem implicar restrição a outros princípios constitucionais, inclusive direitos fundamentais, como a igualdade e os direitos de liberdade. Então, tem-se meios para atingir fins prescritos por princípios constitucionais, cuja aplicação poderá restringir direitos fundamentais, também normas de estatura constitucional. Na hipótese, a lei de tributação extrafiscal tem, na Constituição, tanto normas que a legitimam quanto normas que lhe impõem desconfiança.

Num caso como esse, a proporcionalidade incide como metanorma, a estruturar o modo de aplicação, sobre aquela lei, tanto dos princípios que prescrevem os fins visados pela tributação extrafiscal quanto das normas que prescrevem os direitos fundamentais por ela restringidos: a igualdade e os direitos de liberdade. Com isso, a proporcionalidade concorre, com outras normas, para definir a validade da tributação extrafiscal: a tributação extrafiscal será válida se, além de outros requisitos, resistir ao teste da proporcionalidade. Porque a proporcionalidade serve precisamente para isso: postando-se num plano diverso das normas objeto de aplicação, estrutura a aplicação dessas normas: com ela, afere-se a validade de medida, tomada pelo poder público, para promover a realização de um princípio constitucional - ou mais 
de um. A medida é eleita como meio para atingir a finalidade prescrita por princípio(s) constitucional(is), havendo a relação meio-fim; mas, nisso, acaba por restringir a realização de outra norma constitucional - ou outras normas constitucionais. Aferindo a validade de medida restritiva de direitos fundamentais adotada pelo poder público, e exigindo, para tanto, a demonstração do cumprimento de certos pressupostos, a proporcionalidade serve como controle do arbítrio (ÁVILA, 2012-b, p. 143, $158-160,182-184)$.

É patente o cabimento do exame de proporcionalidade na tributação extrafiscal. Ela sempre deve ter como objetivo a busca de finalidades prescritas por princípios constitucionais. À medida que visa interferir nas condutas socioeconômicas, induzindo a adoção de comportamentos, afeta direitos de liberdade. Surge, aí, a primeira colisão de princípios constitucionais. Além disso, normalmente, cinde o universo de contribuintes entre duas classes: os destinatários da tributação extrafiscal, que terão sua liberdade afetada, e os não destinatários, que, diretamente, não sofrerão os efeitos da existência jurídica da exação. Assim, cria desigualdade. Aparece, então, a segunda colisão de princípios. Colisões que surgem porque a adoção de meios destinados a promover a realização de princípios constitucionais acabam por restringir outros. A validade dessa restrição dependerá, dentre outros critérios, do atendimento à proporcionalidade. A doutrina não titubeia em afirmar a proporcionalidade como um dos critérios de medida da validade da tributação extrafiscal (SCHOUERI, 2005, p. 294-295; ÁVILA, 2009, p. 161-163; VIEIRA, [s.d.], p. 76; VELLOSO, 2010, p. 249 e ss.).

Dizer que a tributação extrafiscal precisa respeitar a proporcionalidade - em sentido amplo de postulado normativo - equivale a dizer que ela só é cabível quando for adequada, necessária e proporcional - em sentido estrito. Os três exames adequação, necessidade e proporcionalidade em sentido estrito - compõem o que, contemporaneamente, entende-se por controle de proporcionalidade (ALEXY, 2008, p. 116-120; 588-611; ÁVILA, 2012-b, p. 187-196).

\section{I Adequação}

O exame da adequação verifica se a tributação extrafiscal contribui adequadamente para promover a realização da finalidade constitucional que lhe serve de fundamento de validade - ou das finalidades. Aqui fica claro que a tributação extrafiscal depende, previamente, de amparo expresso em finalidade prescrita, direta ou indiretamente, na Constituição. Sem esse amparo, nem sequer o exame de proporcionalidade é cabível, pois a tributação extrafiscal já será, desde logo, inválida. Inclusive, há doutrina, decerto minoritária, que inclui a avaliação da existência dessa finalidade constitucional no exame de proporcionalidade, como um primeiro de quatro critérios (SILVA, 2002, p. 35). Assim, para instituir tributação extrafiscal, a primeira providência que o poder público deve adotar é expor, expressamente, em motivação prévia, a finalidade 
que busca com sua inserção no ordenamento. A segunda é, também expressamente, justificar sua adequação.

Será adequada a medida que promova aquela finalidade constitucional. Isso basta. Não é necessário que o poder público demonstre ser, aquela, a melhor medida; que é, dentre todas, a que promove mais, melhor e mais certamente a finalidade constitucional. Basta que demonstre, expressamente, ser uma medida adequada (ÁVILA, 2012-b, p. 187-189). Também, é inexigível que demonstre que a medida concretizará, de uma vez por todas e por si só, a finalidade. Basta que demonstre, por escrito, que a medida contribuirá para que se caminhe nesse sentido - um "fomento" (ÁVILA, 2012-b, p. 190-191; SILVA, 2002, p. 36). Ainda, descabe pretender que o poder público seja obrigado a demonstrar que a medida, concretamente, contribuirá para a promoção da finalidade. Basta demonstrar que, em tese, ela potencialmente contribui, considerando-se o que é possível supor no momento em que a medida é adotada - é incabível, inclusive, pretender que o poder público pudesse levar em consideração elementos inexistentes quando da adoção da medida e que só surgiram posteriormente, sejam esses elementos fáticos, jurídicos, novos conhecimentos e técnicas etc. (ÁVILA, 2012-b, p. 189-190). Mesmo porque, em todos esses casos, e em rigor, seriam demonstrações impossíveis. Só quem ainda acredita em causalidade linear, em infalibilidade do conhecimento e da técnica, e desconhece a ecologia da ação e a complexidade das inter-relações recursivas entre os elementos da realidade em permanente conexão, pode crer que o ser humano seria capaz de escolher um meio para atingir determinado fim, sabendo que aquele meio promove mais, melhor e mais seguramente alguma finalidade, ou que a concretizará inequivocamente, sem que haja possibilidade de desvio. Essa comprovação, em rigor, é impossível; não há ciência capaz de sustentá-la (FOLLONI, 2013, p. 333 e ss.).

Sendo a medida inadequada, ela será, por si só, desproporcional. Sequer será necessário investigar a necessidade. Sendo, porém, adequada, cabe avaliar o cumprimento do segundo requisito.

\subsection{NeCESSIDADE}

O exame da necessidade avalia se a tributação extrafiscal é, dentre as medidas disponíveis para a promoção da finalidade constitucional, a menos restritiva do direito fundamental que colide com aquela finalidade - no caso, a igualdade, ou a liberdade. Se houver meio que promova igualmente aquela finalidade constitucional sem restringir, ou restringindo menos, a isonomia ou a liberdade, ele deverá ser adotado, em lugar do meio mais restritivo. A adoção do meio mais restritivo, diante de alternativas menos restritivas, será comportamento que não obedecerá à proporcionalidade e, portanto, juridicamente ilegítimo.

Como se percebe, há necessidade de dois exames comparativos. Em primeiro lugar, é preciso saber se há meios alternativos - no caso, à tributação extrafiscal pretendida - 
que promovam igualmente a finalidade constitucional. Em segundo lugar, é preciso saber se esses meios alternativos restringem menos os princípios constitucionais colidentes - no caso, a igualdade tributária, ou os direitos de liberdade. E envolve argumentações complexas: e se o meio alternativo fomentar menos a finalidade, mas, em contrapartida, também for menos restritivo do direito colidente? (ÁVILA, 2012-b, p. 192-194)

O primeiro exame, da comparação entre meios, não exige demonstração cabal de que o meio alternativo promove igualmente, em todas as medidas, a finalidade constitucional almejada, pelas mesmas dificuldades descritas em relação ao exame da adequação, e porque há dimensões diferentes nessa igualdade: meios igual ou diferentemente rápidos, custosos, eficazes, poluentes, fáceis, complexos, seguros etc. (ÁVILA, 2012-b, p. 193-194). Já o segundo, da capacidade de restrição a princípios constitucionais colidentes, pode e deve ser feito com todo o rigor que a argumentação jurídica for capaz de fornecer. E, no caso em questão, deve-se recorrer à construção doutrinária e jurisprudencial a respeito da igualdade em geral, e da igualdade tributária em particular, para se testar o grau de restrição dos meios alternativos. O poder público, ao adotar tributação extrafiscal, deve motivar, expressamente, sua opção: demonstrar que verificou meios alternativos e concluiu serem esses meios, razoavelmente equivalentes no que concerne à promoção da finalidade, mais restritivos a outros direitos, como a igualdade tributária; e que, por isso, os descartou e convenceu-se da legitimidade da via eleita.

\subsection{Proporcionalidade}

Por fim, a tributação extrafiscal deve demonstrar-se proporcional em sentido estrito. Esse parece ser o exame mais difícil, pois envolve, como reconhece a doutrina, elevado grau de subjetividade (ÁVILA, 2012-b, p. 195). Isso não significa, porém, que não deva ser levado a efeito - mesmo porque, em muitos casos, também salienta a doutrina, esse exame de proporcionalidade pode conferir adequado controle de racionalidade da decisão tomada pelo poder público (ALEXY, 2008, p. 594).

O exame de proporcionalidade envolve o sopesamento entre as vantagens que, em tese, serão obtidas com a medida avaliada, e as desvantagens decorrentes da restrição a direitos que ela acaba por causar. Assim, se a finalidade que se procura promover tem elevada importância, isso justificará, eventualmente, seja afetado, em certa medida, direito colidente. Para restrições graves a direitos fundamentais, por exemplo, apenas finalidades de elevadíssima relevância constitucional servirão de justificativa aceitável (ALEXY, 2008, p. 593).

É preciso, então, para escapar do arbítrio ou do relativismo, produzir critérios de controle de racionalidade de juízos tradicionalmente tidos por subjetivos, como "vantajoso/desvantajoso", "importante/desimportante", "grave/não grave" etc. Robert Alexy esboça classes de relevância da finalidade a ser promovida e da restrição a 
direitos colidentes para, em seguida, compará-los. A relevância da finalidade é ligada, em sua doutrina, às razões que a justificam, em razões fracas, moderadas e fortes. A restrição a direitos fundamentais é classificada em leve, moderada e séria. Assim, por exemplo, uma restrição leve a um direito fundamental, para promover uma finalidade sustentada por razões fortes, é, sem dúvida, justificável. Uma restrição séria a direitos fundamentais, para promover uma finalidade de relevância baixa, fundada em razões fracas, não. Restrições graves - ou moderadas, ou leves - para finalidades de alta relevância - ou média, ou baixa, respectivamente - levam a impasses teóricos e abrem margem à discricionariedade do poder público: tomar a medida não será desproporcional, tampouco revogá-la. Essa discricionariedade, em princípio, é legítima, e a escolha do órgão competente deve ser respeitada pelo Poder Judiciário (ALEXY, 2008, p. 594-610).

Claro está que determinar a importância da finalidade ou a seriedade da restrição a direito fundamental é algo que a própria proporcionalidade não faz. E fazê-lo, embora em alguns casos seja simples, em outros pode ser extremamente difícil, a gerar séria controvérsia. Aí está o trabalho da jurisprudência e, sobretudo, da doutrina: interpretar, compreender, construir e reconstruir teorias, práticas e significados jurídicos baseados no papel da Constituição no Estado brasileiro do século XXI, no contexto que deriva do pós-guerra do século passado e avança para os problemas contemporâneos.

Antes de concluir, há alguns pontos a aclarar. Direitos de liberdade são direitos fundamentais no constitucionalismo contemporâneo, e desde a aurora do constitucionalismo moderno. Eles, porém, são sempre potencialmente restringidos por medidas de direito econômico, como a tributação extrafiscal. Além deles, a igualdade, em regra, também é restringida pela tributação extrafiscal. Nota-se que a tributação extrafiscal afeta os direitos mais fundamentais no constitucionalismo. No caso da igualdade, um direito com privilégio axiológico em face de outros princípios de estatura constitucional - registra, com precisão, José Souto Maior Borges (1996, p. 31). Isso implica que o ônus argumentativo, para justificar medida do poder público que comprometa a igualdade tributária, como a tributação extrafiscal, é mais acentuado do que o seria se comprometesse outros direitos fundamentais ou outros princípios constitucionais (ÁVILA, 2009, p. 149-160). Não se usa a extrafiscalidade à toa. Eis aí instrumento que não pode ser banalizado no Estado Democrático de Direito.

Por outro lado, certos objetivos constitucionais que podem justificar a tributação extrafiscal sempre terão estatura tão insigne no contexto contemporâneo que, dificilmente, medidas adotadas para sua promoção serão afastadas apenas pela aplicação do critério da proporcionalidade em sentido estrito. A finalidade socioambiental, principalmente considerando a possibilidade concreta de aniquilação da vida digna no planeta, é sempre justificável em razões fortes. Por isso, pode implicar restrições a direitos fundamentais - que, sem vida no planeta, não fazem sentido - inclusive se houver défice epistêmico nas premissas que o suportam. Mesmo que não esteja plena 
e cabalmente comprovado que aquela medida realmente promove a finalidade socioambiental; ou se ela vier para anular ou atenuar os efeitos de conduta não comprovada, de forma plena e cabal, como danosa ao meio ambiente; ainda assim, por precaução, deve ser admitida a plausibilidade da medida. A construção dogmática do princípio da precaução, no direito ambiental, quando ligada à necessidade de sufragar medidas protetivas ao meio ambiente mesmo sem provas científicas robustas de sua eficácia, ou de condenar medidas danosas mesmo sem prova cabal da capacidade de produzir dano, demonstra, aqui, toda a sua relevância (ARAGÃO, 1997, p. 152-156; LEITE; AYALA, 2002, p. 62). A extrafiscalidade, para fins socioambientais, pode e deve ser utilizada com intensidade (MARINS; TEODOROVICZ, 2010, p. 108-109).

Por fim: ao adotar a medida, cabe ao poder público justificar expressamente, por escrito, que ela é adequada, necessária e proporcional. A quem adota a medida resta o dever jurídico de expor, por escrito, os porquês da tributação extrafiscal, sobretudo quando ela atinge a igualdade tributária. E porquês jurídicos, econômicos, sociais, ambientais... todos os que se revelarem pertinentes - os jurídicos, aliás, sempre serão pertinentes, pelo que a doutrina os reclama com toda a razão (VIEIRA, Inédito, p. 20). A exposição de motivos da produção normativa cresce em importância no constitucionalismo contemporâneo, revelando-se crucial e determinante - assim como o exame crítico dessa exposição pelo Poder Judiciário, caso provocado. Sem a fundamentação expressa, a lei será, só por isso, ilegítima. A sanção pelo descumprimento do dever jurídico de justificação da tributação extrafiscal, notadamente quando implica restrição à igualdade tributária, deverá ser a invalidade da norma que a insere no ordenamento - ou, no mínimo, a ampla possibilidade de revisão, pelo Poder Judiciário, de todos os pressupostos - quais? - adotados quando de sua elaboração. O Judiciário terá, inclusive, um ônus que não lhe cabia originariamente: verificar a proporcionalidade da medida seria tarefa inicial do Legislativo; agora, deverá ser feita, ex nihilo, pelo Judiciário. Não há respeito à tripartição de funções que impeça o Judiciário de sindicar uma lei, por exemplo, resultado do desrespeito, pelo órgão do qual emanou, às suas próprias funções constitucionais. Até mesmo as críticas acerca da "vontade do legislador" - que se voltam, sobretudo, à produção teórica da Jurisprudência dos Conceitos alemã e da Escola da Exegese francesa, do século XIX, inclusive a crítica semiótica - devem ser revistas, no contexto do constitucionalismo contemporâneo. Devem olhar para frente, e não apenas para trás.

\section{Conclusão}

No contexto contemporâneo, em que o Estado brasileiro tem se valido frequente e intensamente de tributação extrafiscal para perseguir o atingimento de fins econômicos, é preciso, à doutrina, estudar esse modo específico de exação tributária, caracterizada pela intenção do poder público ao editá-la: a produção de efeitos 
socioeconômico-ambientais concretos. Preocupada com os efeitos nas condutas intersubjetivas, e por isso caracterizada, é uma tributação na qual o aspecto pragmático prepondera: seu objetivo é induzir alguém a fazer ou a deixar de fazer alguma coisa, para além de pagar o tributo - ou, até mesmo, independentemente disso.

Sendo assim, é uma tributação destinada a separar os contribuintes em duas classes: aqueles que não adotavam a conduta que se intenta induzir e que, por isso mesmo, serão pretensamente afetados pela tributação extrafiscal em seus direitos de liberdade; e aqueles que já adotavam a conduta pretendida, e que, por isso, não serão, ao menos diretamente, atingidos pela existência jurídica da exação. Cinde-se os contribuintes entre os destinatários da tributação extrafiscal, por ela afetados, e os não destinatários. Cria-se, portanto, desigualdade, restringindo-se o direito fundamental à isonomia tributária.

Em regra, a capacidade contributiva é o critério de igualdade no direito tributário. Mas, também em regra, esse critério mostra-se inadequado nos casos de tributação extrafiscal. Este trabalho demonstrou, porém, que, dentro da classe dos destinatários, a capacidade contributiva, muitas vezes, será critério relevante, tanto para testar a eficácia da tributação extrafiscal quanto para evitar efeitos desiguais nos contribuintes. Por outro lado, para aferir a validade da desigualdade interclasses, a capacidade contributiva não é critério adequado. Nesse caso, a restrição à igualdade está sujeita ao controle de proporcionalidade: a tributação extrafiscal será válida quando, fundada na promoção de finalidade constitucionalmente contemplada, for adequada para a promoção dessa finalidade; necessária, diante dos direitos que acaba por restringir e de outras medidas que poderiam ser tão adequadas quanto ela, mas menos restritivas; e proporcional, também diante desses direitos. A demonstração, expressa, por escrito, em justificativa prévia, dessas adequação, necessidade e proporcionalidade, é dever jurídico constitucional do órgão que adota a medida - no caso, do Poder Legislativo, ao editar a tributação extrafiscal, submetida à legalidade tributária.

Uma vez que a igualdade é um direito com inegável e evidente privilégio abstrato e axiológico constitucional, restringi-la envolve razões de relevância ímpar e carga argumentativa especialmente forte. Por isso, extrafiscalidade não pode ser usada à toa. Ela deve ser usada para a promoção, apenas, dos fins constitucionais mais elevados. Dentre eles, por exemplo e sem dúvida, os fins socioambientais e de sustentabilidade da vida no planeta.

: ARTIGO APROVADO (20/02/2014) : RECEBIDO EM 24/01/2013 


\section{NOTAS}

1 Sobre os diferentes graus de ilicitude no constitucionalismo contemporâneo e, especificamente, no direito brasileiro (FOLLONI, 2012).

2 Para a capacidade contributiva como protetora do mínimo existencial nos tributos extrafiscais, cf. Becker (1972, p. 457). Para a capacidade contributiva como vedação a tributos extrafiscais com efeito de confisco, cf. Torres (1999, p. 136). Para ambos, cf. Vieira (2013, p. 32).

\section{REFERÊNCIAS BIBLIOGRÁFICAS}

ALEXY, Robert. Teoria dos direitos fundamentais. Tradução Virgílio Afonso da Silva. São Paulo: Malheiros, 2008. ARAGÃO, Maria Alexandra de Sousa. O princípio do poluidor pagador: pedra angular da política comunitária do ambiente. Col. Stvdia Ivridica, n. 23. Coimbra: Universidade de Coimbra, 1997.

ATALIBA, Geraldo. Sistema constitucional tributário brasileiro. São Paulo: RT, 1968.

ÁVILA, Humberto. A distinção entre princípios e regras e a redefinição do dever de proporcionalidade. Revista Diálogo Jurídico, Ano 1, v. 1, n. 4, jul. 2001.

. Sistema constitucional tributário. 5. ed. São Paulo: Saraiva, 2012. (2012-a)

. Teoria da igualdade tributária. 2. ed. São Paulo: Malheiros, 2009.

. Teoria dos princípios: da definição à aplicação dos princípios jurídicos. 13. ed. São Paulo: Malheiros, 2012. (2012-b)

BECKER, Alfredo Augusto. Teoria geral do direito tributário. 2. ed. São Paulo: Saraiva, 1972.

BLUMENSTEIN, Ernst. Sistema di diritto delle imposte. Milano: Giuffrè, 1951.

BORGES, José Souto Maior. Ciência feliz. Tradução Juan Carlos Panez Solorzano. Lima: Palestra, 2012. Introdução ao direito financeiro. 2. ed. São Paulo: Max Limonad, 1998.

Significação do princípio da isonomia na Constituição de 1988. Revista Trimestral de Direito Público, São

Paulo, n. 15, 1996.

Teoria geral da isenção tributária. 3. ed. São Paulo: Malheiros, 2001.

CARRAZZA, Roque Antonio. Curso de direito constitucional tributário. 27. ed. São Paulo: Malheiros, 2011. . Imposto sobre a renda: perfil constitucional e temas específicos. São Paulo: Malheiros, 2005.

CARVALHO, Aurora Tomazini de. Curso de teoria geral do direito: o constructivismo lógico-semântico. São Paulo: Noeses, 2009.

COSTA, Alcides Jorge. Prefácio. In: SCHOUERI, Luís Eduardo. Normas tributárias indutoras e intervenção econômica. Rio de Janeiro: Forense, 2005.

COSTA, Regina Helena. Princípio da capacidade contributiva. 3. ed. São Paulo: Malheiros, 2003.

FOLLONI, André. Ciência do direito tributário no Brasil: crítica e perspectivas a partir de José Souto Maior Borges. São Paulo: Saraiva, 2013.

Socioambientalidade, tributo e o artigo $3^{\circ}$ do Código Tributário Nacional. Revista Tributária e de Finanças Públicas. São Paulo, v. 105, jul./ago. 2012, p. 264-266.

GRIZIOTTI, Benvenuto. Principios de ciencia de las finanzas. Buenos Aires: Depalma, 1959.

HERRERA MOLINA, Pedro M. Capacidad económica y sistema fiscal. Madrid: Marcial Pons, 1998.

LEITE, José Rubens Morato; AYALA, Patrick de Araújo. Direito ambiental na sociedade de risco. Rio de Janeiro: Forense Universitária, 2002.

MARINS, James; TEODOROVICZ, Jeferson. Extrafiscalidade socioambiental. Revista Tributária e de Finanças Públicas, n. 90, jan. / fev., 2010.

MARTINS-COSTA, Judith. Almiro do Couto e Silva e a ressignificação do princípio da segurança jurídica na relação entre Estado e cidadão. In: ÁVILA, Humberto (org.). Fundamentos do Estado de Direito: estudos em homenagem a Almiro do Couto e Silva. São Paulo: Malheiros, 2005.

NABAIS, José Casalta. O dever fundamental de pagar impostos. Coimbra: Almedina, 1998.

SCHOUERI, Luís Eduardo. Normas tributárias indutoras e intervenção econômica. Rio de Janeiro: Forense, 2005. SILVA, Virgílio Afonso da. O razoável e o proporcional. Revista dos Tribunais, São Paulo, n. 798, abr. 2002. 
TIPKE, Klaus; LANG, Joachim. Direito Tributário. V. I. Tradução Luiz Dória Furquim. Porto Alegre: Sergio Fabris, 2008.

TORRES, Ricardo Lobo. Tratado de direito constitucional, financeiro e tributário. V. III: os direitos humanos e a tributação: imunidades e isonomia. Rio de Janeiro: Renovar, 1999.

VELLOSO, Andrei Pitten. O princípio da isonomia tributária: da teoria da igualdade ao controle das desigualdades impositivas. Porto Alegre: Livraria do Advogado, 2010.

VIEIRA, José Roberto. A extrafiscalidade da Lei n. 12.715/2012 e a capacidade contributiva: a convivência do lobo e do cordeiro? Revista de Direito Tributário, São Paulo, n. 118, jun. 2013, p. 18-42.

IPI e extrafiscalidade. Revista de Direito Tributário, São Paulo, n. 91, [s.d.].

VOGEL, Klaus. Die abschichtung von Rechtsfolgen im Steuerrecht. Steuer und Wirtschaft - StuW, n. 2, 1977.

André Folloni

Rua Visconde do Rio Branco, 1630, cj. 1507

Centro - 80420-210

Curitiba - PR - Brasil

andrefollonidgmail.com
Professor Adjunto da Pontifícia Universidade

Católica do Paraná 